\title{
Comparative Analysis of Most Common Language used for Communication between Basic Schools Students in Rural and Urban Areas in Ghana
}

\author{
Bright Nkrumah $^{1 *}$, Mercy Ansah ${ }^{2}$ \\ ${ }^{1}$ Lecturer, Modern Languages Department (Chinese Section), University of Ghana, Ghana \\ ${ }^{2}$ Teacher, Egyirifa M/A Basic school, Mfansteman Municipal Assembly, Central Region. Ghana.
}

*Corresponding Author: Bright Nkrumah, Lecturer, Modern Languages Department (Chinese Section), University of Ghana, Ghana

\begin{abstract}
Both Ghanaian language and English language are considered at different level of education as subject of study and medium of instruction in the Ghanaian basic school. The research aimed at analyzing comparatively the most common language for communication between basic school students in urban and rural areas in Ghana respectively. One hundred (100) students were considered for the study and structured questionnaires was used for the data collection. The study adopted a multi-stage and a descriptive crosssectional for the sampling with an (SPSS version 21) for the analysis. From indications, the most commonly used language for communication in schools is English language. The students in rural areas use Ghanaian language more than those in urban while students in urban areas also use English language predominately for communication than rural dwellers. The factors that influence the choice of communication were found to be as result of internal and external factors. It is recommended that educational policy maker and stakeholders should reconsider enforcement of educational policy. Stakeholders of Ghana education must adopt strategies to ensure that students are given the necessary attention to the reading subjects and the writing as well.
\end{abstract}

Key words: Language communication, Ghana, basic school students.

\section{INTRODUCTION}

Language used in communication is very key in our daily lives to express ideas, information and feelings from one person or group to execute an action. Most African countries including Ghana, is a multilingual nation. Multilingualism has paved its way into various walks of life including education. In Ghana, apparently between 45 and 60 people are known to be an indigenous people situated in various communities. The sustainability of linguistic and cultural changes has been an issue to effective national communication and its alignment.

The History of education in Ghana dates back to 1592. Schools in Ghana, then Gold Coast were set up by the Danish, Dutch and English merchants in their Forts (Christianborg Castle Accra, Danish, Elmina Castle. Portuguese then Dutch and Cape Coast Castle. British) to educate their mulatto children by native women. Unmistakably linked to the implementation of formal education in Ghana were the Christian Missionaries, who realized that in order to spread the word of God they needed well-educated local assistants. (Agbozo, 2015)

John Von Richelieu, one of the Danish Governors to Ghana, approached the Basel Mission Society of Switzerland in 1828. They played an important role in establishing an education network in Ghana. Representatives of this organisation were able to convince the Chiefs of Ghana in 1832 to send their children to the Government School at Osu. Thus, creating acceptance for formal education. They also concentrated on the interior of Ghana, away from the European influences on the coast. Besides reading, writing and arithmetic, workshops were organized for students to acquire practical skills. Carpentry, masonry, blacksmithing, shoemaking and sewing for girls were taught, as well as practical agriculture, medical and health education. One of the greatest achievements of the Basel Mission Society was the transcription of local languages (Twi, Ewe and Ga languages) to facilitate education 
and the spreading of the Gospel. By 1894, they had established a Training College, 3 grammar schools, seven boarding schools for boys and girls and 98-day schools. (ibid). In Ghana, multingulism is seen as a widely spoken language use. it has been realized that indigenous and foreign language are used numerous in the areas of governace, education, the media and commerce, However, in Ghana all the educational values, norms, principles and policies are entangled in the history of Ghana. It is necessitated that an attempt needs to be made to address the multicity forms of language to make sure that the students have knowledge and the requisite skills in at least one of the native language and English. Sometimes the Ghanaian language and the English language are used in a dissimilar way which raises a lot of concern, which needs to be look at critically with other subjects used in schools.

\subsection{Research Questions}

- What is the commonly used language for communication among Ghanaian students?

- Does place of residence has effects on the choice of language for communication?

- What are the factors that necessitate the choice of language for communication among Ghanaian students?

\section{LITERATURE REVIEW}

\subsection{Language-In-Education in Ghana}

The Ghanaian laid down principles and policies has gone through series of transformation and pollicising the way back diachronic swayed some Europeans to live in different settlement on the gold coast such as the Dutch, British and the Portuguese. on the $6^{\text {th }}$ of march 1957. Ghana gained its independence from the then colonial masters and became independent associates of the commonwealth nations, which was ran by Kwame Nkrumah who in diverse ways change the country to a republic state, now known as Ghana. With the inception of the formal education and the subsequent use of English language as medium of instruction, the indigenous language were seen as "inadequate " as teaching media(Bamgbose,2000) is very crucial and attest to the fact that, it has been very helpful in today's administration which was used as a sole language after the then independence, pertaining to the indigenous native language, it was seen and used in different ways both at home and in the market place as well.

\subsection{Ghana's Language-In-Education Policy}

Madsen et al. (2014) demonstrate that educational policy decision aims at ensuring effective management of schools to ensure increased learning for all students regardless of race, ethnicity, or economic status. Over the Centuries education has had different goals, from spreading the Gospel to creating an elite group to run the colony. After Ghana gained its independence in $6^{\text {th }}$ day of March in 1957, the education system, then modelled on the British system, has undergone a series of reforms. Especially the reforms in the 1980's geared towards the education system away from purely academic to more in tune with the nations manpower needs. The present structure of education, which starts at the age of 6 years, consists of 6 years of primary education, 3 years of Junior Secondary School, 3 years of Senior Secondary School and 4 years University or courses at other tertiary institutions, the first 9 years form the basic education are free and compulsory.

The sole official language of instruction throughout the Ghanaian educational system is English. Students may study in any of eleven local languages for much of the first three years, after which English becomes the medium. Students continue to study a Ghanaian language as well as French as classroom subjects through at least the ninth grade.

The curriculum used in schools is work-oriented. The Primary School level curriculum consists of English, Ghanaian language and Culture, Mathematics, Environmental studies, Integrated Science, Religious and Moral Education and physical activities such as Music, Dance and Physical Education. The Junior High School level makes a distinction between Agricultural and General science and incorporates subjects such as Pre- Vocational Skills and Pre-technical skills. Also, Social Studies and French as a 3rd language were added.

These indigenous languages are distributed among a speaker population of approximately $26,428,000$ (United Nations Department of Economic and Social Affairs, 2013, cited in Lewis, Simons and Fennig, 2015) people spread across ten administrative regions. 


\subsection{Ethno-Linguistic}

The Akan speaking language is the dominates ethno-language used in Ghana, example they are made up of different ethnicity and sub-ethnic groups in their various domains. This group alone constitutes $47.5 \%$ of the population of Ghana. The other major language groups are Mole-Dagbane 16.6\%; Ewe 13.9\%; Ga-Adangbe 7.4\%, and Mande 1.1\% (Ghana Statistical Services, 2012). Many schools in Ghana use the English language in teaching and other native language as well. However many homes in Ghana use the Akan language frequently with their children to let them understand some of the things naturally and at a faster rate as far as the language is concerned.

In addition to English, there are nine government-sponsored languages which are to be used as mediums of instruction in the first three years of primary school and taught as subjects from the fourth year of basic education and beyond. Presently, Ghana has a 2-9-3-4(3) educational structure (OwuEwie \& Edu-Buandoh, 2014).

Table1. Language usage in Ghanaian Educational Structure.

\begin{tabular}{|l|l|l|}
\hline Level & No. Of Years & Medium of Instruction \\
\hline Pre-Basic (Kindergarten) & 2 & Ghanaian Language \\
\hline Lower Primary school & 3 & Ghanaian Language \\
\hline Upper primary school & 3 & Ghanaian Language \\
\hline Junior High School & 3 & English \\
\hline Senior High School & 3 & English \\
\hline Universities and University Colleges & 4 & English \\
\hline $\begin{array}{l}\text { Other Tertiary institutions (Teacher, Nursing, Midwifery } \\
\text { training colleges, etc) }\end{array}$ & 3 & English \\
\hline
\end{tabular}

Source: (Ministry of Education Science and Sports, teaching syllabus for English Language, 2007).

\subsection{Benefit of Languages}

The use of language is a subject of global significance. It helps to build strong organisational culture both at home and our work places. It brings flexibility and creativity. It is through language that we develop our thoughts, shape our experiences, explore our customs, structure our communities, construct our laws, articulate our values and give expression to our hopes and ideas (Australian Council of State School Organizations, 2007). Mother tongue is known to be one of the factors that promote solid foundation for learning in the early years (Dea et al.2014; Carol et al., 2010).

\section{Methodology}

\subsection{Study Design}

A cross sectional design study was adopted and used for the collection of data, once from the sampled group within a brief span of time. In a cross sectional study any variable of interest that exists in a given population is measured once at a specific point in time (Hulley et al 2001:107).

The study adopted a survey in the collection of data. According to Bowling (2002:195-196) surveys are quantitative research tools used during the process of data collection from a sample of the population of interest commonly through face to face interviews. Surveys help to establish the level of a given characteristic of the phenomenon of interest in a given population.

The data collected through demographics such as age, type of settlement, educational level, ethnicity background and language use for communication in school and out school. There was no unbiased intervention done to the respondent before the data was collected. The researcher spoke to the students and explained the questions to them in a manner in which they will understand.

\subsection{Population Study}

The study was conducted in Ghana and the population set for the study are urban and rural basic school students. One hundred (100) students were considered for the study and structured questionnaires was used for the data collection. The study adopted a multi-stage and a descriptive cross-sectional for the sampling purposes.

\subsection{Sampling Method}

Samples for a research were selected from the population. Studying the whole population would have greatly enhanced the outcome of this research. However, as stated by Best and Kahn (1989), the 
primary purpose of research is not only to discover principles that have universal applications, but also to study a whole population to arrive at generalizations that would have been impracticable, if not impossible to do so.

The research employed multi-stage sampling techniques. During the first three stages, employed simple random sampling without replacement, using balloting technique to select region, district and communities for first, second and third stage respectively. Non-probability sampling techniques was used to select the respondents from the selected communities. For the non-probability sampling technique, purposive sampling was used to ensure that the only teenage mothers/pregnant women were selected for the study. A purposive sampling was also used to select the one hundred (100) sampled basic school students, fifty each from both rural and urban areas, The study considered only participants who are readily available and agree to participate in a study indicates that convenience sampling is often called accidental.

\subsection{Sample Size}

Sample size of 100 was considered for the study to ascertain the size sample for the study. The procedure is shown below;

$$
n=\frac{\alpha^{2} p(1-p)}{\varepsilon^{2}}
$$

Where;

(n) means the sample size.

(a) means the confidence level.

(p) it pertains to the estimated proportion or the prevalence of an attribute that is present in the population expressed in proportion of one. $\varepsilon$ is the margin of error.

If $\alpha$ is 1.96 (using a confidence level of $95 \%$ ), $p$ is 0.1 and $\varepsilon$ is $0.05(5 \%)$ then,

$$
\begin{aligned}
& n=\frac{1.96^{2} 0.1(1-0.1)}{0.05^{2}} \\
& n=138
\end{aligned}
$$

Therefore, calculated sample size for the study was 138 respondents. But due to inadequate of time one hundred (100) samples were used for the study without jeopardizing the reliability and precision of the research outcome.

\section{Methods of Data Collection}

The study considered both primary source data from administered questionnaire and observation as well.

\subsection{Research Instrument}

A structured questionnaire was the main data collection tool used for the study. The questionnaire was made up of open and closed- ended questions (multiple choice type) to ensure the collection of both quantitative and qualitative data.

\subsection{Data Analysis Procedures}

At this stage the method of organizing, summarizing and presenting the data in a convenient manner was used to deal with the data collected. The two forms of descriptive statistics was applied in the study for the graphical technique and the numerical technique. (SPSS Version 21) was used for windows was used to generate the outputs.

\subsection{Pre-Testing}

The questionnaire which was developed by the researcher was used to test the twenty (20) students on the bases selected for the basic school students in Agona West district in the central region of Ghana. The pre-testing of questionnaire was carried out to confirm the suitability and sustainability of the questionnaire for the intended purpose. This helped the researcher in redesigning it better and estimates the amount of time and money that was required to collect and process the data efficiently and effectively. 
Pre-testing of the instrument and the method of collecting data were conducted in order to identify the challenges and shortfalls in the data collection process. The pre-testing was also to check the randomness and independence of the sampling units. Again, it was done to ensure that questions in a questionnaire were understandable and unambiguous (Robson, 2002). This helped to modify some of the problems of one's design.

Assistance was given to those who had difficulty in responding to some of the questions in the questionnaire in an unbiased manner.

To ensure the validity of the items, the questionnaires were crosschecked and then controlled using the result from the pre-testing. This was to reduce errors to its barest minimum and eliminate threat to validity of the research.

\subsection{Ethical Consideration}

Ethical clearance was sought from the various head teachers of the institutions considered for the study as well as the consent of the students were duly sought. All procedures were geared towards the ethical values and rules emerged.

\section{RESULTS AND DISCUSSION}

Table2. Commonly used language for communication among Ghanaian students.

\begin{tabular}{|l|l|l|l|l|l|}
\hline LANGUAGE & $\begin{array}{l}\text { In class room } \\
\text { with classmate }\end{array}$ & $\begin{array}{l}\text { In school outside } \\
\text { classroom }\end{array}$ & $\begin{array}{l}\text { At } \\
\text { home }\end{array}$ & $\begin{array}{l}\text { Within the } \\
\text { community }\end{array}$ & $\begin{array}{l}\text { Language used } \\
\text { for teaching }\end{array}$ \\
\hline English & 67 & 62 & 28 & 4 & 89 \\
\hline Ghanaian language & 8 & 11 & 24 & 83 & 4 \\
\hline $\begin{array}{l}\text { Both English and } \\
\text { Ghanaian language }\end{array}$ & 22 & 27 & 49 & 13 & 7 \\
\hline Other language & 3 & 0 & 1 & 0 & 0 \\
\hline
\end{tabular}

Source: Fieldwork, 2018.

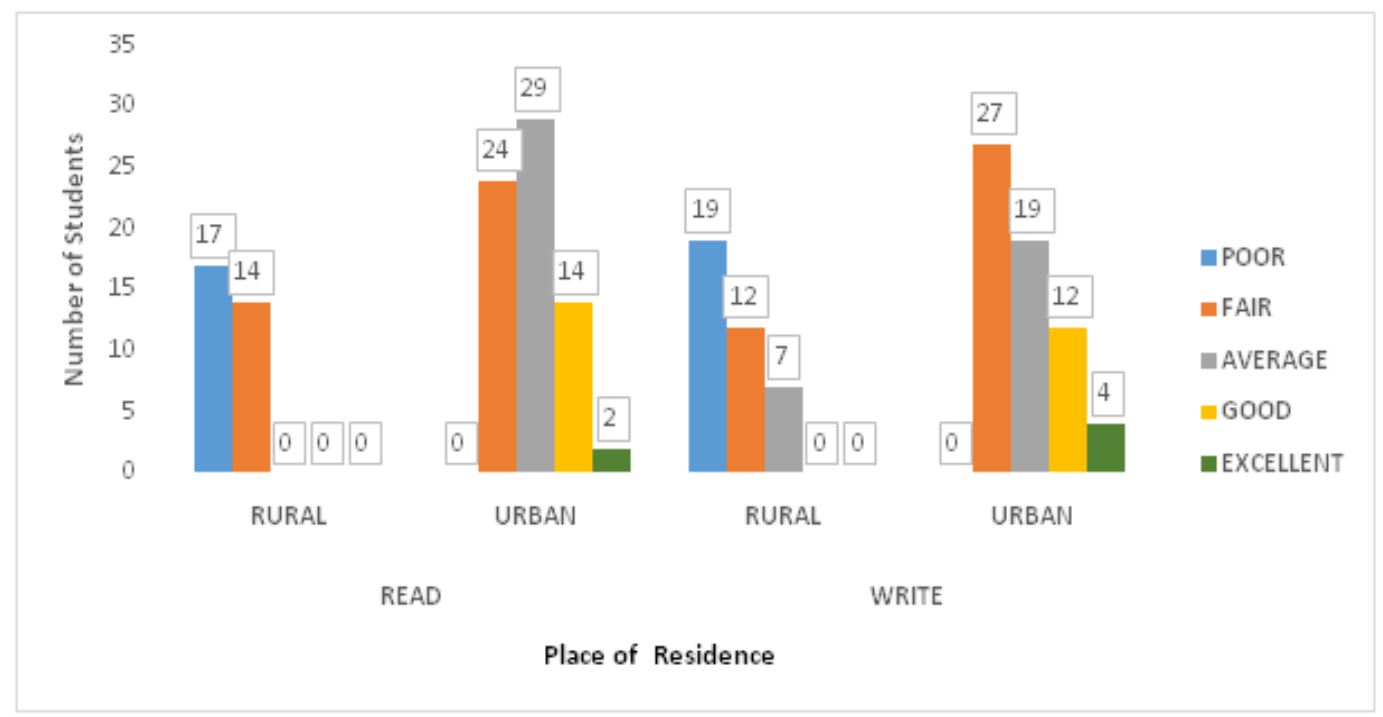

Figure1. Ability to Read and Write the Spoken Language

Source: Fieldwork, 2018.

The study revealed that, most common language for communication was found to be English since greater percentage of them use English for communication with classmates, school mates as well as a medium for teaching. Ghanaian language is commonly used outside both school and home but dominantly used within the various communities. The choice of combining English and Ghanaian language was dominantly used at home. This implies that the commonly used language for communication among Basic School students in Ghana is dependents on the location, thus where they find themselves a particular time and place.

As reading and writing is inevitable ingredients in communication, the researcher inquired the proficiency ability of studied students in both reading and writing of the language they speak. 
Comparative Analysis of Most Common Language used for Communication between Basic Schools Students in Rural and Urban Areas in Ghana

The study revealed that, students in urban areas read and write better than their counterpart students in rural areas.

Table3. Place of residence * choice of language for communication.

\begin{tabular}{|l|l|l|l|l|}
\hline & & English & Ghanaian Language & Both English and Ghanaian Language \\
\hline $\begin{array}{l}\text { Place of } \\
\text { residence }\end{array}$ & Rural & 6 & 18 & 9 \\
\cline { 2 - 5 } & Urban & 51 & 5 & 11 \\
\hline
\end{tabular}

Pearson Correlation value: $\quad 0.68$

The relationship and the strength of association between place of residence of basic school students and the choice of language for communication was considered in the research. It was found out the students in rural areas use Ghanaian language than those in urban. Besides, students in urban areas also use English language mostly for communication than their rural dwellers counterpart. The correlation value of 0.68 indicate that, the more urbanized the residence, the more likely the students speak English. Finally, the more students study in urban centers the higher the English speaker and vice versa for rural dwellers and the use of Ghanaian language.

Table4. Factors that influence language choices for communication among Ghanaian students.

\begin{tabular}{|c|c|c|c|c|c|}
\hline & English & $\begin{array}{l}\text { Ghanaian } \\
\text { language }\end{array}$ & $\begin{array}{l}\text { Both English and } \\
\text { Ghana language }\end{array}$ & Other language \\
\hline \multirow[t]{4}{*}{ Education level } & $\mathrm{Kg}$ & 7 & 89 & 4 & 0 \\
\hline & Lower primary & 9 & 72 & 19 & 0 \\
\hline & Upper primary & 19 & 49 & 32 & 0 \\
\hline & JHS & 39 & 27 & 34 & 0 \\
\hline \multirow{4}{*}{$\begin{array}{l}\text { Type of } \\
\text { School }\end{array}$} & Private & 33 & 0 & 0 & 0 \\
\hline & Public & 14 & 8 & 22 & 3 \\
\hline & Mission & 18 & 0 & 0 & 0 \\
\hline & Others & 2 & 0 & 0 & 0 \\
\hline \multirow{2}{*}{$\begin{array}{ll}\begin{array}{l}\text { Place } \\
\text { residence }\end{array} & \text { of } \\
\end{array}$} & Rural & 0 & 6 & 22 & 3 \\
\hline & Urban & 63 & 2 & 4 & 0 \\
\hline \multicolumn{2}{|c|}{ Compulsory to use by higher authority } & $72 \%$ & $10 \%$ & $17 \%$ & $1 \%$ \\
\hline \multicolumn{2}{|c|}{$\begin{array}{l}\text { Conversant with its usage than any } \\
\text { other language }\end{array}$} & $21 \%$ & $66 \%$ & $12 \%$ & $1 \%$ \\
\hline \multirow{2}{*}{\multicolumn{2}{|c|}{ For academic's purposes }} & $63 \%$ & $3 \%$ & $34 \%$ & $0 \%$ \\
\hline & & $11 \%$ & $71 \%$ & $17 \%$ & $1 \%$ \\
\hline
\end{tabular}

Source: Fieldwork, 2018.

Though, choice of language for communication may be influenced by either external and internal factors or both as the subject will choose consciously or unconsciously. Understanding the influences on subjects' language choices helps us to better interpret the possible reasons behind these choices' language for communication. This aim is to establish the factors that influence language choices language commonly used in communication in school and outside school as well medium of instructions in various classrooms.

The study revealed that, both external and internal factors influence their choice of language for communication. Level of education has influence on the choice of language since the study revealed that greater percentage (89\%) of pupil in kindergarten chose Ghanaian language as their language for communication. Those basic school students in both lower primary and upper primary were found be using Ghana language mostly in communication with percentage of $72 \%$ and $49 \%$ respectively. The study also revealed that, most of the students in Junior high school preferred using English language for communication recorded 39\%. The level of the student is a determinant for the choice of language for communication since the study revealed that the use of English language in as the student go higher in educational level. The choice of English language increased in numbers from kindergarten through primary school to junior high school as the use of Ghanaian language decreased as the student attain higher level of education. The number of students who use both English and Ghanaian language as language for communication also increased steadily as the student move from lower level to higher level in education. This implies that, educational level factor for the choice of language.

The study revealed that, the type of school also determines the language choice in school and even affect their choices even at home. It was found that students in primary school are compelled to use 
English for irrespective their level of education as those in public schools mostly use Ghanaian languages for communication whiles missionary and charitable schools mostly prefer using both languages for communication.

Influence of authorities has also been found to be determinant for the choice of communication language among students in basic school. Authorities with regards to school authorities, elite elderly persons in communities as well as parents. Most students are obliged to use only English for communication in school and after probing further from those who used English language for communication at home, it was found out their parents have attained tertiary formal educated.

Again, as revealed by the research findings, most of the respondents $(66 \%)$ are conversant with the used of Ghanaian language communication as most student in Junior High school studied revealed that they use English language for communication for only academic purposes.

The internal factor such as "it is my mother tongue" was also found to be a factor for choice of language for communication. Greater portion of students studied revealed that $71 \%$ of them use Ghanaian language for communication because they know it is their mother tongue so they need to be well abreast with its usage, thus speaking, writing as well as reading.

\section{CONCLUSION AND RECOMMENDATIONS}

\subsection{Conclusion}

The research was gathered to examined and analysed comparatively the most common language used for communication between basic school students in rural and urban areas in Ghana with aim of determining commonly used language for communication among Ghanaian students, evaluate the effects on the choice of language for communication and exploring factors that necessitate the choice of language for communication among Ghanaian students.

It was determining that the most commonly used language for communication in school is English language, outside school (at home) was found to be mixture of English and Ghanaian languages and outside school premises and home, was found that majority of the students studied use Ghanaian languages for communication.

The effect of association between place of residence of basic school students and the choice of language for communication was considered in the research. It was found out the students in rural areas use Ghanaian language than those in urban. Besides, students in urban areas also use English language mostly for communication than their rural dwellers counterpart.

The factors that influence the choice of communication were found to be as result of internal and external factors. The internal factor is the intrinsic thought that the subjects perceptive a language as inheritance from parents. Thus "It is my mother tongue". The external factors were the factors that the subject considered from outside. Thus, the external factors revealed by the research include; type of school the subject attends, level of education, existing protocols that has been set be superior either in school or outside school and the language the subject found more comfortable using in communication.

\subsection{Recommendations}

The research revealed that, most of the existing educational language policies in Ghana education systems are not duly adhered to by some school authorities. For instance, it was established that most schools used English language as medium of instruction throughout the levels of basic education which is in contrary to the use of Ghanaian language as medium of instruction for Kindergarten and lower primary school especially the private school and some missionary school while most public schools especially those in rural areas use Ghanaian languages as medium of instruction even in upper primary school and Junior High School level which is also in contradiction to the policy of English as medium of instruction. It is therefore recommended that, educational policy maker should reconsider its enforcement.

Again, it is urged that stakeholders of Ghana education must ensure improvement reading and writing of the languages the students use for communication. The study revealed that most students cannot read and write the language they seek well neither being English nor Ghanaian Language. Lastly, the study revealed that some student preferred that other languages such as French should be added to the sole official English language for both public and academic use. Teachers should also endeavour to 
use practical demonstrations, symbols and signs in communicating when teaching students for simple understanding as far as the English language is concerned.

\section{REFERENCES}

[1] Bamgbose, A. (2000). Languge and exclusion. Piscataway, New Jersey: Transaction Publishers Pronuation in west Africa. Students in Linguistic Sciences Volume 30, Numbers 2(fall 2000), pp 185-198.

[2] Best, J. K. ((1989)). Research in education (8th) Needham hights.

[3] Bowling, C. \&. ((2002-195-196)). Shapping Communities through extentio programmes. Journal of extention available.

[4] Carol, B., \& Behanu, B. M. ((2010)). The meduim of instruction of primary school of Ethiopia: A study and its implementation for multinlingual education.

[5] Dea, T. T. ((2014)). Challenges in use of mother tongue education as meduim of instruction in primary school for quality enhancemnt.

[6] G. S. ((2012)). Ghana Statisticsl Service.

[7] Hulley, B. C. ((2001:107)).

[8] Madsen MM, L. J. (2014).

[9] Ministry of Education Science and Sports. ((2007)). Teaching syllabus for English Languge.

[10] Owu-Ewie, C. E.-B. ((2014)). Living with negative attitude towards the study of L1 in Ghanaian Senoir High Schools (SHS). Ghana Jounal of Linguistics.

[11] MA: Cascadilla Proceedings Project.pp76-85.

[12] Robson, C, Research in a methodogical fram .Journal of Arts,Sicence and Commerce Voulme 3 july 2012.14

\section{AUTHORS' BIOGRAPHY}

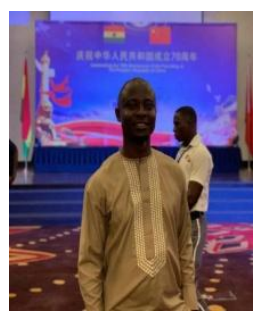

Dr. Bright Nkrumah, is a lecturer at the University of Ghana, Modern Languages Departments (Chinese Language Section) in Ghana. Dr. Nkrumah received his B.A Degree in Chinese Language and Literature at Xianyang Normal University China, Master's Degree in Teaching Chinese to Speakers of other languages in Xi'an International Studies University China, and completed his Doctorate Degree in Chinese Linguistic (Studies of Modern Chinese Characters) from Northwest University in China.

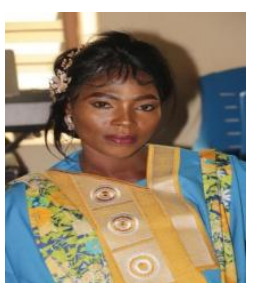

Mrs. Mercy Ansah, carries a Diploma in Basic Education from the University of Cape Coast and specialized in teaching Ghanaian Language. She currently teaches at Egyirifa M/A Basic School in the Mfansteman District of Central Region Ghana.

Citation: Bright Nkrumah, Mercy Ansah. "Comparative Analysis of Most Common Language used for Communication between Basic Schools Students in Rural and Urban Areas in Ghana" International Journal of Humanities Social Sciences and Education (IJHSSE), vol 7, no. 5, 2020, pp. 52-59. doi: http://dx.doi.org/10.20431/2349-0381.0705007.

Copyright: () 2020 Authors. This is an open-access article distributed under the terms of the Creative Commons Attribution License, which permits unrestricted use, distribution, and reproduction in any medium, provided the original author and source are credited. 